\title{
La comunicación en las redes sociales. Movistar y los adolescentes
}

\author{
Estrella MARTÍNEZ-RODRIGO \\ Universidad de Granada \\ emrodrigo@ugr.es \\ María José Palacios-Trassierra \\ Universidad de Málaga \\ mjosept@uma.es
}

\begin{abstract}
Resumen:
Las redes sociales han abierto inéditas posibilidades al marketing y a la publicidad on line, convirtiéndose en eficaces canales de comunicación donde crear comunidades virtuales en torno a las marcas. En la presente investigación se han analizado las estrategias comunicativas de Movistar en la red social Tuenti para conectar con su público objetivo con el fin de influir en sus decisiones de compra y conseguir una afiliación de los adolescentes a la marca. Entre los resultados destaca el acierto de Movistar en el horario y periodicidad de sus mensajes, en el carácter racional de dichos mensajes y en el recurso a las imágenes. Estas estrategias han provocado una alta interacción por parte de los jóvenes con la marca y entre ellos mismos.
\end{abstract}

Palabras clave: Redes sociales; Publicidad; adolescentes; Tuenti; Movistar; comunicación

\section{Communication in social networks. Movistar and teenagers}

\begin{abstract}
:
Social networking has provided unprecedented opportunities for marketing and advertising on line, becoming effective communication channels which create virtual communities around brands. In this investigation will analyze the communication strategies Movistar in Tuenti social network to connect with their target audience in order to influence their purchasing decisions and get a affiliation of adolescents to the brand. The results show the success of Movistar in the time and frequency of messages, the rationality of these messages and the use of images. These strategies have resulted a high interaction by young people with the brand and each other.
\end{abstract}

Key Words: Social networks; advertising; teenagers; Tuenti; Movistar; communication.

\section{Referencia normalizada:}

Martínez Rodrigo, E. y Palacios Trassierra, M. J. (2014): La comunicación en las redes sociales. Movistar y los adolescentes. Historia y Comunicación Social. Vol. 19. Núm. Especial Febrero. Págs. 377-386.

Sumario: 1. Introducción. 2. Publicidad en Tuenti. 3. Metodología. 4. Análisis de resultados. 4.1. Frecuencia y periodicidad de estados publicados. 4.2. Empleo de imágenes como apoyo gráfico. 4.3. Carácter emocional o racional de los mensajes. 4.4. Participación por diferencia sexual y diálogo entre los usuarios de la comunidad Movistar. 5. Conclusiones. 6. Referencias bibliográficas. 


\section{Introducción}

No cabe duda de que las redes sociales se han convertido en uno de los fenómenos más importantes de Internet en el último lustro. Las nuevas tecnologías digitales llevan consigo nuevas formas de interacción social que influyen cada vez más en las decisiones de compra de los consumidores y, por tanto, en la imagen de las empresas. Escuchar, conversar y relacionarse con los clientes a través de las nuevas tecnologías supone una transformación total de la cultura empresarial (Castelló, 2010: 15). La necesidad de adaptarse a los nuevos tiempos ha hecho que el marketing haya pasado de tratar al consumidor como un simple cliente, a considerar sus intereses y sentimientos para buscar un feedback continuo. En esa tarea las estrategias tradicionales no son suficientes, por lo que las empresas se han visto obligadas a buscar herramientas adicionales capaces de ofrecer esos servicios, y las redes sociales se han convertido en el escenario idóneo para conseguirlo (Pajuelo, 2012: 38).

En España, Facebook es considerada para un público más adulto aunque está ganando terreno entre los jóvenes, pero la red social que se ha posicionado como la preferida por una gran mayoría (80\%) de adolescentes españoles es Tuenti, según el Informe de la generación 2.0 (2010).

Esta red social se ha convertido en poco tiempo en una de las plataformas más importantes de Internet. Además, la mayoría de los usuarios tienen registrados en sus perfiles datos muy interesantes, como la edad, sexo, lugar de residencia, gustos, hábitos, fotos, contactos de amigos, vídeos, etc., segmentación de gran utilidad para las empresas y anunciantes, ya que al conocer con precisión a qué tipo de persona se están dirigiendo, pueden presentar a cada tipo de consumidor aquellos productos por los que podría estar interesado.

Por lo tanto, no es de extrañar que cada vez más se dediquen mayores presupuestos publicitarios a las redes sociales (cada vez más innovadoras en sus formatos), frente a otro tipo de soportes, ya que si los usuarios pasan tanto tiempo en estos sitios, las probabilidades de que vean sus anuncios, se hagan seguidores de la marca o empresa y se interesen por sus productos o servicios aumentan considerablemente. No obstante, las marcas deben ser conscientes del cambio de paradigma que han propiciado las redes sociales en el ámbito publicitario y la regularidad que exige su presencia en estas plataformas. Los elementos y las características propias de la comunicación han cambiado, así como los roles asumidos por anunciantes y usuarios (Martínez-Rodrigo \& Sánchez-Martín, 2012: 9).

Desde los inicios de Tuenti y su posterior creación de Tuenti páginas, Movistar fue una de las primeras empresas en sacar partido a esta nueva herramienta para interactuar y acercarse a los usuarios de la comunidad Tuenti; no en vano es su empresa creadora. Es una de las marcas con más fans en dicha red social y cuenta con una de las páginas más interactivas y dinámicas. 


\section{Metodología}

En la presente investigación se tienen por objetivos principales los siguientes: analizar los recursos visuales y lingüísticos empleados por Movistar para atraer la atención de su target, descubrir si la marca emplea mensajes racionales o emocionales en sus publicaciones con la intención de influir en el comportamiento de sus fans, así como examinar la relación existente entre los propios usuarios de la comunidad Movistar y la marca.

La metodología empleada para conseguir los objetivos de esta investigación es el análisis de contenido. El campo de estudio es el comprendido entre el 1 de diciembre de 2012 y el 31 de enero de 2013, coincidiendo con la campaña de Navidad de Movistar. El universo se compone de la totalidad de entradas publicadas (76) por Movistar en su página de Tuenti, además de todas las respuestas emitidas (569) por los fans de la marca. Para la interpretación de los datos se ha realizado una ficha metodológica en la que se observarán los siguientes aspectos:

- Fecha y hora de publicación por Movistar en su página de Tuenti, para medir la frecuencia y periodicidad de actualización.

- Frecuencia de recurso a la fotografía, como apoyo gráfico a la información publicada y elemento clarificador del texto.

- Carácter racional o emocional del mensaje:

- Comunicación entre los usuarios de la comunidad y Movistar.

\section{La publicidad en Tuenti}

Tuenti, con 15 millones de usuarios registrados, se ha establecido como el sitio web y móvil más importante en nuestro país. Esta red social no deja de crecer tanto en cantidad de usuarios como en volumen de tráfico. Según comenta Muriel (2012), registra 700 millones de páginas vistas al mes y los usuarios pasan en esta red social un tiempo medio de 100 minutos al día, lo que representa uno de los niveles de engagement más altos del sector.

Cuenta con un posicionamiento definido por un perfil joven; según datos del estudio de Cocktail Analysis en su quinta Oleada (2013), el 59\% de los usuarios son menores de 25 años, coincidiendo con la edad media de esta red social y con el segmento de población más intenso y activo en internet y en las TIC en general. El $56 \%$ de los usuarios son hombres y el $44 \%$ mujeres. Los usuarios de Tuenti recurren a esta red social fundamentalmente para comunicarse con sus contactos (el 55\%) y compartir fotos con los amigos (37\%). En cuanto a la relación que tienen con las marcas, un $41 \%$ de ellos afirma haber tenido contacto con alguna empresa o marca. Sus principales objetivos son: acceder a descuentos o beneficiarse de ofertas especia- 
les (33\%), participar en juegos, aplicaciones o concursos (24\%) e interés por seguir a empresas o marcas.

Las marcas encuentran en Tuenti productos publicitarios más innovadores que los formatos on-line tradicionales, formatos que buscan más el engagement de calidad que ser molestos para los usuarios. Muchos anunciantes encuentran en esta red social un target exclusivamente joven, más complicado de hallar en otras redes, por lo que ven en este canal la oportunidad de publicitarse y lanzar campañas para ellos. La publicidad de Tuenti se basa en la hipersegmentación de todos los formatos publicitarios (por sexo, edad y provincia), y en una gran cobertura, para que el mensaje llegue a un amplio target. Cabe destacar que la cobertura alcanza un $91 \%$ en uno de los segmentos de edad más interesantes para la mayoría de los anunciantes, de 14-35 años, y con nuevos formatos audiovisuales centrados en el branding. Como comenta Fernández Pérez (2009), la segmentación de la audiencia en Tuenti permite poner en contacto a las marcas con aquellas personas que podrían estar interesadas en sus productos o servicios, por lo tanto, se evitaría molestar al resto de usuarios que no se ajustan a los perfiles para sus campañas de publicidad.

Los primeros formatos publicitarios en Tuenti fueron el evento patrocinado y Tuenti páginas. Gracias a su éxito, se fueron creando nuevas herramientas de comunicación para las marcas. En septiembre de 2012, se lanzaron los nuevos formatos disponibles, entre los cuales se distinguen 5 categorías de publicidad: social, vídeo, mobile, ads y exclusive. Además de estas categorías, se ofrecen acciones $A d$ hoc especiales para las empresas, como la cuenta atrás, emoticonos y felicitaciones de cumpleaños.

En esta investigación nos centraremos en Tuenti Páginas puesto que es el formato publicitario que presenta una interacción más directa y fluida de la marca con sus fans. Movistar fue una de las primeras empresas en utilizar este servicio, creando un perfil corporativo muy dinámico y atractivo para los usuarios de la red social. Además, es la marca con mayor número de fans en esta red social -777.840 a fecha de 8 de octubre de 2013-, tanto si lo comparamos con otras compañías de telefonía móvil, como con empresas de otros sectores.

\section{Análisis de los resultados}

\subsection{Frecuencia y periodicidad de estados publicados}

La actividad de Movistar ha sido diaria durante el periodo de tiempo investigado; se ha actualizado el perfil corporativo de lunes a viernes, y no se ha hecho los fines de semanas ni las jornadas de fiesta nacional como los días 6,8 y 25 de diciembre, 1 y 6 de enero. Su actividad incrementó ligeramente, ya que en diciembre de 2012 (un $2,3 \%$ respecto a enero de 2013). La explicación de este aumento de actividad podría encontrarse en que la época de Navidad, principalmente las fechas cercanas a días festivos como Nochebuena y Nochevieja, los jóvenes están de vacaciones y pasan 
más tiempo en las redes sociales para felicitar a familiares y amigos, planificar las salidas, comprar regalos navideños o de Reyes, aprovechando las ofertas especiales de esas fechas navideña, etc.

Por otro lado, en ambos meses se ha registrado mayor número de publicaciones por la mañana-un $70 \%$ en diciembre y un $67,56 \%$ en enero-, alcanzando la hora punta entre las 12 y las $14 \mathrm{~h}$. Resulta acertada la elección de este horario puesto que los mensajes aparecerían en las actualizaciones recientes del timeline de Tuenti de los adolescentes y tendrían más impacto, ya que suelen revistar sus redes sociales nada más salir de clase o durante la hora del almuerzo en casa. Sin embargo, las actualizaciones por la tarde han sido del $30 \%$, siendo las horas más habituales para publicar entre las $16 \mathrm{~h}$ y las $19 \mathrm{~h}$.

Por último, es conveniente destacar que Movistar en ocasiones añade un nuevo comentario en la misma publicación con la intención de ampliar la información que había indicado en la publicación de estado, como puede verse en el siguiente gráfico:

Imagen 1. Comentario de Movistar en su publicación.

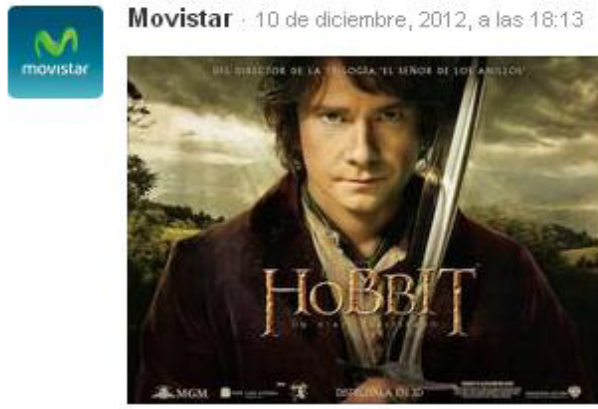

Si estás pensando contratar Movistar Fusión TV, ven a la Flagship en Gran Vía 28, y te regalamos 2 entradas para preestreno El Hobbit

Movistar 10 de diciembre, 2012, a las 18:13

Además, podrás disfrutarla en Movistar Imagenio en abril del 2013. En cines el 14 de diciembre.

Fuente: www.tuenti.com

Parece que la causa está en la limitación de los 140 caracteres que se pueden escribir en un estado de Tuenti, mientras que la extensión para realizar un comentario a un estado es mucho mayor, lo que en ocasiones puede resultar de gran ayuda para los fans, que cuentan con una información más detallada. Sin embargo, encontramos en esta práctica un aspecto negativo para la marca, ya que esta información podría pasar desapercibida en aquellos estados con mucha interacción y participación de los usuarios.

La cantidad de publicaciones en el mismo estado de Movistar fue el doble en diciembre $(32,5 \%)$ que en enero $(16,2 \%)$, esto es debido principalmente, al gran 
número de promociones anunciadas durante este mes, en relación con la campaña de Navidad, eventos culturales, concursos etc. que requerían una información mayor para aclarar las características o condiciones.

\subsection{Empleo de imágenes como apoyo gráfico}

No cabe duda que el empleo de imágenes hace los mensajes más llamativos y atractivos. Además, debido a su poder clarificador, la imagen ayuda a decodificar el texto y comprender mejor el mensaje que se pretende transmitir. Esta práctica sirve de gran ayuda puesto que, como comenta Spang (2009), la imagen atrae la curiosidad del espectador, tanto si tiene relación directa con el producto anunciado como si no, además de su papel informativo y ambientador del contexto o situación que se pretende presentar. En el análisis que hemos llevado a cabo, se ha comprobado una relación directa entre el empleo de imágenes y la interacción; es decir, aquellas publicaciones que acudían a este recurso han tenido unos niveles de participación más elevados. Durante los meses de investigación, el $60 \%$ de las publicaciones contenían imágenes, y una de las funciones más empleadas ha sido la de sugerir: elegir una imagen que describa el contenido del texto, que le aporte fuerza, que lo apoye o complemente.

Durante el mes de diciembre el 50\% de las fotografías ilustraban teléfonos móviles, promoción de tarifas y otros servicios ofertados por Movistar. Con este recurso se pretende captar la atención de los seguidores y persuadirles, mostrándoles los productos y descuentos exclusivos de los que se podrán beneficiar si deciden apostar por la marca. Sin embargo, en el mes de enero de 2013 se produce un cambio, ya que el $46,15 \%$ de las fotografías ilustraban sorteos en los que los seguidores podrían participar y conseguir pases para entrenar con los técnicos de grandes equipos de fútbol como el Real Madrid o el Atlético de Madrid. Imágenes muy persuasivas para incentivar a los fans a participar y dejarse llevar por su pasión futbolera. En definitiva, el empleo de fotografías u otras imágenes resulta muy efectivo, puesto que hacen los estados más ilustrativos y reflejan visualmente cualidades que el texto solo no podría expresar. Además, la imagen aporta viralidad al mensaje, ya que aquellas imágenes curiosas o interesantes son muy propensas a ser compartidas.

\subsection{Carácter emocional o racional de los mensajes}

En el panorama actual, con tanta saturación publicitaria, y ofertas tan variadas de productos cada vez más parecidos, el reto de las empresas no puede ser otro que diferenciarse. No cabe duda de que en nuestra sociedad han cobrado cada vez más peso el lenguaje emocional y los valores correspondientes, por lo que aquellas marcas o productos que buscan destacar optan por recurrir cada vez más a una publicidad de tipo emotivo. Conectar y acercarse al consumidor de esta forma se ha convertido en uno de los objetivos principales de muchas empresas: satisfacer los deseos de los consumidores despertando sus sentimientos más sociales o humanos. Esta técnica puede resultar muy efectiva si se emplea correctamente. Sin embargo, hemos obser- 
vado que Movistar tan solo ha recurrido a ella en el 18\% de sus publicaciones. Estos mensajes apelan a las emociones de los seguidores a través de imágenes sugerentes que acompañan al texto de la publicación. Podemos ver un ejemplo en el siguiente gráfico:

Imagen 2. Apelación a la emoción de los seguidores.

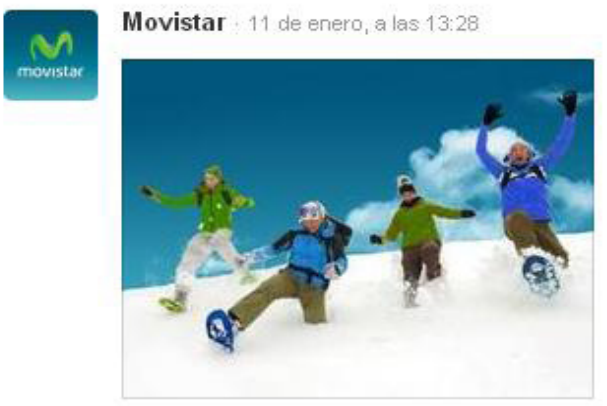

A que os apetece ir 3 días a esquiar con los 3 amigos que queráis y con una suite a vuestra disposición? Entra en $\mathbf{Q}$ http://bit. Iy/N/xe.J07

Fuente: www.tuenti.com

El texto tiene un mensaje marcadamente emocional y estimula a responder positivamente a la pregunta, que incita a hacer click en el enlace. Este mensaje se ve complementado con la fotografía, que refuerza el impulso emocional del texto. Como podemos observar, muestra a cuatro jóvenes divirtiéndose juntos en la nieve, lo que transmite varios valores importantes en esas edades: poder elegir los amigos a los que invitará, disfrutar con ellos practicando un deporte de cierto riesgo, y hacerlo durante varios días, lejos del lugar en el que se mueven habitualmente. Así pues, esta estrategia resulta muy eficaz, ya que fomenta la participación para conseguir un regalo tan completo gracias a Movistar. Además, para llegar al subconsciente y posicionarse en la mente de los consumidores, la empresa plasma sus colores corporativos -azul, blanco y verde- en la ropa de los adolescentes.

A pesar de algunos casos como el que acabamos de comentar, la mayoría de los mensajes publicados por Movistar (82\%) ofrecen contenidos informativos, fáciles de entender y que aportan argumentos sobre el acierto de comprar un producto o contratar una tarifa debido al ahorro que le aportará. Es decir, en el periodo analizado, el target de Movistar lo constituye un consumidor más racional que se ve obligado a dejar de lado los argumentos emocionales-por el momento innecesarios para él-, y busca una compra más inteligente y efectiva que le permita administrar mejor sus escasos ingresos. 
4.4. Participación por diferencia sexual y diálogo entre los usuarios de la comunidad Movistar

Durante el periodo de nuestra de investigación, la participación de los seguidores de Movistar ha estado representada por el sexo masculino $(71,8 \%)$, sobre todo en enero de 2013. Una posible causa parece ser que durante este mes tuvieron lugar gran cantidad de concursos que sorteaban pases para entrenar con los técnicos de grandes equipos de fútbol: temáticas y premios de especial interés para un perfil varonil principalmente. Estos resultados confirman los datos presentados por el Observatorio de Redes Sociales de Cocktail Analysis (2012) en su cuarta Oleada, los cuales exponen que en Tuenti predominan los usuarios de sexo masculino (56\%) frente al femenino (44\%).

Por el contrario, si analizamos el diálogo de la marca con sus seguidores, encontramos que las chicas mantienen más conversaciones con Movistar y están más predispuestas a realizar comentarios o preguntas sobre diversos temas. Los comentarios publicados por ellas -el $50 \%$ en diciembre y el 18,26\% en enero- fueron diálogos directos con la empresa, en algunos casos favorables y en otros negativos, para mostrar su descontento con los servicios de la compañía.

Por otro lado, merece la pena subrayar la gran cantidad de conversaciones establecidas entre los propios usuarios que forman parte de la comunidad de fans de Movistar en Tuenti: el 50\% de las intervenciones en diciembre y más del $80 \%$ en enero. De hecho, estas comunicaciones han recibido mayor número de comentarios que aquellas relaciones establecidas entre Movistar y sus seguidores.

La razón que explicaría este hecho de que los adolescentes prefieran comunicarse entre ellos y no con la empresa podría ser el apoyo que encuentran en la comunidad cuando pretenden presionar a la empresa para terminar con abusos o malas prácticas comerciales, una unión que hace la fuerza. Sin embargo, estos casos no representan la totalidad de los comentarios o conversaciones entre dichos usuarios: en muchos casos se limitan a debatir entre ellos sobre cuáles son sus equipos o jugadores preferidos, qué móviles consideran mejores, etc. La base de estos diálogos son debates, opiniones o sugerencias sobre los temas lanzados por Movistar en sus publicaciones de estado. Se comprueba así que las noticias que transmite la marca suscitan el interés de los adolescentes y generan el debate; por lo tanto, se cumple el objetivo de la información, además de la permanencia de los usuarios en la plataforma.

\section{Conclusiones}

La actualización del perfil corporativo de Movistar en Tuenti se lleva a cabo en un periodo, horario y frecuencia muy acertados, y se traducen en muy buenos resultados de interacción de los fans con la marca. 
La comunidad de fans de Movistar ha sido activa y participativa durante el periodo de tiempo investigado, gracias a que los temas tratados -tecnología, ocio, deporte, concursos- han respondido a los intereses del target de esta red social. Además, es importante destacar que la mayor parte de las temáticas hacen referencia indirecta, de forma hábil y sutil, a la propia marca. Por lo tanto, se trata de una apropiada estrategia de Movistar que le posiciona como una empresa actual que informa de los temas más interesantes del momento.

Muy efectivo ha sido el recurso al empleo de fotografías ya que ha otorgado un atractivo especial a las publicaciones de estado. Una vez más, se ha hecho evidente la eficacia de esta práctica para cautivar y estimular el interés de los seguidores de cualquier red social. Además, en unas fechas tan destacadas como Navidad donde existe una predisposición mayor a gastar el dinero en regalos para los seres más queridos, la persona indecisa se dejará cautivar por el poder seductor de la imagen y se decantará por ese producto publicitado, que exaltará sus ventajas y cualidades hasta convertirse en único para el cliente en el mercado.

Por lo que se refiere al contenido de los mensajes, ha tenido un carácter mucho más racional que emocional. En general, Movistar ha empleado una publicidad fundamentada en argumentos lógicos dirigidos a la mente de sus consumidores para concienciarles de la conveniencia de obtener sus productos o servicios, lo que llama la atención teniendo en cuenta las edades del target, en las que suele predominar el factor emocional

En cuanto al sector más participativo de Movistar, está formado por un perfil masculino, crítico con la compañía frente al femenino, que suele aportar un matiz más positivo en sus comentarios e incluso defender explícitamente a la marca en ciertas ocasiones.

Finalmente, es importante señalar que la comunicación en dentro de la red social Tuenti entre los propios usuarios de la comunidad de Movistar se convierte en un foro de ayuda que puede ser muy útil para otros consumidores. El reto de la empresa está en controlar el hilo de estas conversaciones para evitar el riesgo de que puedan ocasionar una crisis de reputación a la marca. En tal caso, debería debe primar ante todo la rapidez, la transparencia y la comunicación por parte de la empresa.

\section{Bibliografía}

CASTELLÓ MARTÍNEZ, A. (2010). Estrategias empresariales en la web 2-0: las redes sociales online. Alicante: Club Universitario.

FERNÁNDEZ PÉREZ, J. (2009). "Tuenti: El innovador milagro de la red social made in Spain". En MK: Marketing+ventas, no 250, p. 36-42.

INTERACTIVE ADVERTISING BUREAU (2013). IV Estudio anual Redes Sociales. Disponible en: http://www.iabspain.net/redes-sociales/ [14-07-2013]. 
MARTÍNEZ-RODRIGO, E.; SÁNCHEZ-MARTÍN, L. (2012). "Comunicación entre menores y marcas". En Estudios sobre el mensaje periodístico, Vol. 18, noviembre, p.589-598. Disponible en: http://revistas.ucm.es/index.php/ESMP/article/ view/40938/39188 [4-08-2013].

MURIEL, S. (2012). “¡Ya somos 14 millones!”. Disponible en: http://corporate. tuenti.com/es/blog/2012/6? page=1 [22-06-2013].

PAJUELO, L. (2012). "Redes Sociales: el nuevo boca a boca". En IP MARK, 779, p. $38-41$.

SÁNCHEZ BURÓN, A.; FERNÁNDEZ MARTÍN, M.P. (2010). Informe Generación 2.0: Hábitos de los adolescentes en el uso de las redes sociales. Estudio comparativo entre Comunidades Autónomas. Madrid: Universidad Camilo José Cela.

SPANG, K. (2009). Persuasión. Fundamentos de la retórica. Pamplona: Eunsa.

THE COCKTAIL ANALYSIS (2012). IV Oleada del Observatorio de redes sociales. Disponible en: http://www.slideshare.net/TCAnalysis/4-oleada-observatorio-de-redes-sociales?ref=http://the-cocktail.com/blog/posts/4a-oleada-del-observatorio-de-redes-sociales-207. [30-07- 2013].

THE COCKTAIL ANALYSIS (2013). V Oleada del Observatorio de redes sociales. Disponible en: http://tcanalysis.com/blog/posts/infografia-5-oleada-observatorio-redes-sociales. [04-10-2013].

\section{Las autoras}

Dra. Estrella Martínez Rodrigo. Es profesora de la Facultad de Comunicación y Documentación de la Universidad de Granada. Autora de numerosos artículos científicos, libros y capítulos de libros, su investigación gira en torno al análisis de la web 2.0 y del discurso audiovisual, on-line y publicitario, prestando particular atención a sus efectos y a sus implicaciones educativas y de género. Es la responsable del Grupo de Investigación CiberAV "Cibercultura, Procesos Comunicativos y Medios Audiovisuales" (SEJ 058) de la Junta de Andalucía. Ha participado también en diversos proyectos de investigación europeos y latinoamericanos. Es miembro fundador de la Sociedad Latina de Comunicación Social, y miembro de la Junta directiva del Grupo Comunicar y de la Asociación Andaluza de Semiótica.

$\mathrm{M}^{\mathrm{a}}$ José Palacios-Trassierra. Licenciada en Publicidad y Relaciones Públicas por la Universidad de Málaga. Máster en Gestión estratégica e innovación en comunicación. Es Investigadora en Comunicación audiovisual, ha participado con aportaciones en diversos congresos internacionales, y es autora de diversas publicaciones relacionadas con la Comunicación digital. Ha impartido numerosos cursos sobre Cibercultura en colaboración con distintas entidades. Ha formado parte del Grupo de investigación "Comunicación y moda" de la Universidad de Málaga y actualmente es miembro del grupo de investigación CiberAV "Cibercultura, Procesos Comunicativos y Medios audiovisuales" (SEJ-508) de la Universidad de Granada. 